Please do not remove this page

RMIT

UNIVERSITY

\title{
Balancing exertion experiences
}

Mueller, Florian Floyd; Vetere, Frank; Gibbs, Martin; Edge, D; Agamanolis, S; Sheridan, J; Heer, J

https://researchrepository.rmit.edu.au/esploro/outputs/9921858706201341/filesAndLinks?institution=61RMIT_INST\&index=null

Mueller, F. F., Vetere, F., Gibbs, M., Edge, D., Agamanolis, S., Sheridan, J., \& Heer, J. (2012). Balancing exertion experiences. $\mathrm{CHI}$ '12: Proceedings of the SIGCHI Conference on Human Factors in Computing Systems, 1853-1862. https://doi.org/10.1145/2207676.2208322

Document Version: Accepted Manuscript

Published Version: https://doi.org/10.1145/2207676.2208322

Repository homepage: https://researchrepository.rmit.edu.au

(C) 2012 ACM

Downloaded On 2023/04/27 00:18:05 +1000

Please do not remove this page 
Thank you for downloading this document from the RMIT Research Repository.

The RMIT Research Repository is an open access database showcasing the research outputs of RMIT University researchers.

RMIT Research Repository: http://researchbank.rmit.edu.au/

\section{Citation:}

Mueller, F, Vetere, F, Gibbs, M, Edge, D, Agamanolis, S, Sheridan, J and Heer, J 2012, 'Balancing exertion experiences', in Joseph A. Konstan, Ed H. Chi, Kristina Höök (ed.) $\mathrm{CHI}$ '12: Proceedings of the SIGCHI Conference on Human Factors in Computing Systems, United States, 05 - 12 May 2012, pp. 1853-1862.

See this record in the RMIT Research Repository at:

http://researchbank.rmit.edu.au/view/rmit:18273

Version: Accepted Manuscript

Copyright Statement: (c) 2012 ACM

Link to Published Version:

http://dx.doi.org/10.1145/2207676.2208322 
(C) ACM 2012. This is the author's version of the work. It is posted here for your personal use. Not for redistribution. The definitive Version of Record was published in CHI '12 Proceedings of the SIGCHI Conference on Human Factors in Computing Systems, http://dx.doi.org/10.1145/2207676.2208322. 


\title{
Balancing Exertion Experiences
}

\author{
Florian 'Floyd' Mueller ${ }^{1,2,6,3}$, Frank Vetere ${ }^{2}$, Martin R. Gibbs ${ }^{2}$, Darren Edge ${ }^{3}$, \\ Stefan Agamanolis ${ }^{4}$, Jennifer G. Sheridan ${ }^{5}$, Jeffrey Heer ${ }^{6}$ RMIT University
Melbourne
Australia \\ ${ }^{1}$ Exertion Games Lab

$\begin{array}{cccc}{ }^{3} \text { Microsoft } & { }^{4} \text { Akron } & { }^{5} \text { BigDog } & { }^{6} \mathrm{HCI} \\ \begin{array}{c}\text { Research Asia } \\ \text { Children's }\end{array} & \text { Interactive } & \text { Group } \\ \begin{array}{c}\text { Beijing } \\ \text { Hospital }\end{array} & \text { London } & \text { Stanford } \\ \begin{array}{ccc}\text { People's Republic } \\ \text { of China }\end{array} & \text { Ukron, OH } & \text { UK } & \text { USA } \\ & & \end{array}$ \\ Department of Computing \\ and Information Systems \\ The University of \\ Melbourne \\ Australia

Rin \\ of China
}

floyd@exertiongameslab.org, \{f.vetere,martin.gibbs\}@unimelb.edu.au, darren.edge@microsoft.com, stefan@agamanolis.com, jennifer@bigdoginteractive.com,jheer@cs.stanford.edu

\begin{abstract}
Exercising with others, such as jogging in pairs, can be socially engaging. However, if exercise partners have different fitness levels then the activity can be too strenuous for one and not challenging enough for the other, compromising engagement and health benefits. Our system, Jogging over a Distance, uses heart rate data and spatialized sound to create an equitable, balanced experience between joggers of different fitness levels who are geographically distributed. We extend this prior work by analyzing the experience of 32 joggers to detail how specific design features facilitated, and hindered, an engaging and balanced exertion experience. With this knowledge, we derive four dimensions that describe a design space for balancing exertion experiences: Measurement, Adjustment, Presentation and Control. We also present six design tactics for creating balanced exertion experiences described by these dimensions. By aiding designers in supporting participants of different physical abilities, we hope to increase participation and engagement with physical activity and facilitate the many benefits it brings about.
\end{abstract}

\section{Author Keywords}

Exertion Interface; whole-body interaction; exergame; handicap; heart rate scaling; dynamic difficulty adjustment; dynamic game balancing; sport; running; jogging

ACM Classification Keywords: H.5.2. [Information Interfaces and Presentation]: User Interfaces Miscellaneous.

General terms: Design, Human Factors

Permission to make digital or hard copies of all or part of this work for personal or classroom use is granted without fee provided that copies are not made or distributed for profit or commercial advantage and that copies bear this notice and the full citation on the first page. To copy otherwise, or republish, to post on servers or to redistribute to lists, requires prior specific permission and/or a fee.

CHI'12, May 5-10, 2012, Austin, Texas, USA.

Copyright 2012 ACM 978-1-4503-1015-4/12/05 ...\$10.00.

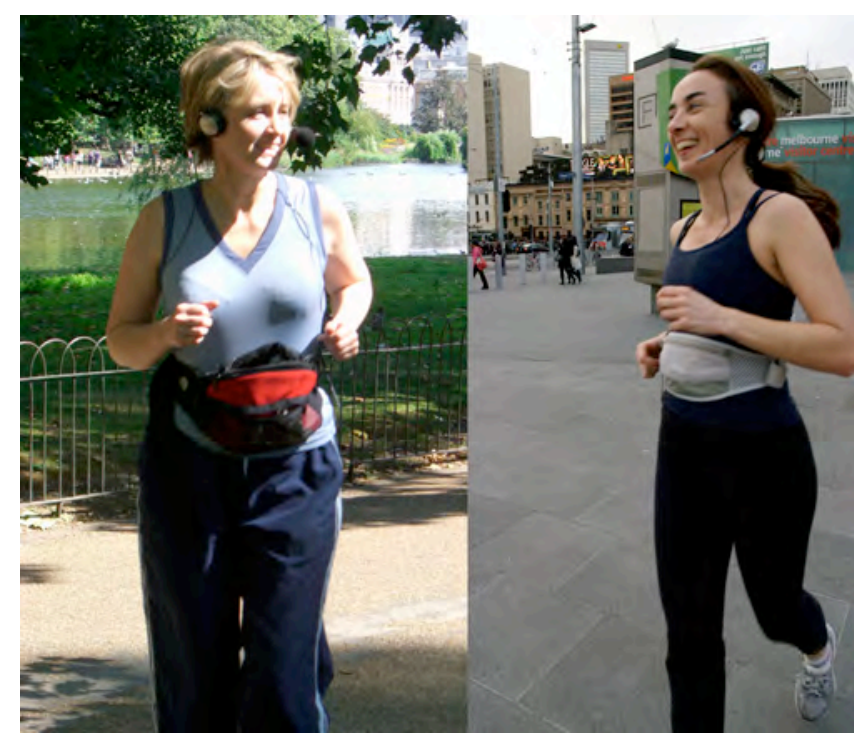

Figure 1. Jogging over a Distance.

\section{INTRODUCTION}

Understanding the role of physical exertion in interactions with technology is a blossoming field in HCI. By "exertion" interactions we mean interactions with technology that require intense physical effort from the user [17]. Recent developments that support and facilitate exertion are sports tracking systems on mobile phones [22], augmented exercise bikes that motivate users through digital content [31] and game controllers such as Nintendo's Wiimotes, Sony's PlayStation Move and Microsoft's Kinect. Recent research has also explored how to design for these exertion experiences [18]. Supporting exertion is important, as it can facilitate health benefits as well as address the obesity epidemic.

We believe that these systems can benefit from social engagement. Previous HCI work has shown that exertion 
interactions can be intertwined with social experiences [7, $13,14,17]$. This is not surprising, as research in sports and physical exercise has long suggested that exercising with others can have both social and exertion benefits [33].

The central contribution of this paper is a framework for the design of balanced exertion experiences, which we scaffold in two mutually supportive ways. First, we draw on sports and game literature and existing exertion systems to communicate the broad boundaries of potential analysis. Next, we investigate the experiences of users who have engaged with an exertion system designed for the purpose of creating a balanced experience.

We focus on jogging, i.e. running at a leisurely pace. We argue that a key factor in making jogging more engaging for participants is allowing them to jog with friends. We have highlighted in previous work how joggers enjoy jogging with friends both because it is an opportunity to socialize and because these social relationships motivate them to go jogging in the first place [24]. Unlike serious runners, social joggers see talking while running as beneficial to the activity, because they use it to motivate and challenge one another. Participants chat while jogging, since their primary focus is not performance improvement. The ability to talk can also serve as a check that one is not running too fast, in line with doctor recommendations [25].

However, jogging friends might have different skills and abilities, making an equitable experience difficult. Joggers need to negotiate an equal jogging pace, which often makes the exercise more physically challenging for one participant. This potentially decreases engagement in the activity and exposes participants to unhealthy exhaustion levels. In addition, a jogger's ability to talk, and hence engage in social conversation, is limited when running beyond one's abilities [25]. If joggers agree to adjust their pace to the slower runner, the fitter participant will feel less challenged and engaged, thus limiting his or her health benefits. In sum, different fitness levels of joggers mean compromising between social benefits, engagement and health benefits. On the other hand, one might argue that the constant negotiation of speed and the ability to increase the pace to "push" each other to higher exertion levels [24] is the essence of social jogging and contributes to its appeal.

Jogging over a Distance (Fig. 1) aims to explore this area: it supports jogging friends who want to run together but who are geographically separated and have potentially different fitness levels. It is a mobile system that allows joggers to motivate one another over an integrated audio channel delivered via headsets. The audio is spatialized so that joggers can experience a sense of being "ahead", "behind" or "next to" each other through the headset. The spatialization is controlled by the difference in participant's heart rate relative to their target heart rate, allowing joggers with different fitness levels to run together, something they cannot do when co-located.
In previous research, we described the ethnographic work that influenced the design of our system [24] and demonstrated that Jogging over a Distance can facilitate a shared exertion experience despite distance [21]. In this paper, we build on this and draw on existing and new data to investigate how designers can balance exertion experiences. By balance we mean incorporating technological support so that the exertion activity is not too strenuous, yet challenges participants and facilitates the social character of the experience. We use Jogging over a Distance as a research vehicle to explore these aims and have therefore conducted further investigations into the use of the system as well as captured new data beyond the initial work. By using a system that supports mediated interactions we have a unique opportunity to gain insights into how interactive technologies can balance exertion. In particular, our augmentation of both social and exertion aspects in Jogging over a Distance make it the ideal research vehicle for this kind of experiential analysis (unlike, for example, co-located exercise bike balancing [31] which only tackles the exertion aspect).

We used captured conversations as they occurred during the jogging activities as well as heart rate logs and interview data from 32 participants who used Jogging over a Distance across three countries. We investigated if and how our design facilitated a balanced, yet challenging and engaging experience. With this knowledge, we derived four dimensions that describe a design space for balancing exertion experiences: Measurement, Adjustment, Presentation and Control. In order to aid designers in navigating this design space, we also used our craft knowledge from designing and deploying the system across three countries to present six design tactics for creating engaging balanced exertion experiences, which we describe using the dimensions mentioned above.

Our design space and associated tactics can be applied to the design of other exertion systems that might need to accommodate different fitness levels, such as treadmills and exercise bikes that are used in social contexts, for example gyms, and also to mobile exercise support systems such as those implemented in sports watches and mobile phones. Our work might also inform the design of movementcontrolled social games such as those supported by the Wii, Move and Kinect, to accommodate different skills and abilities of family members [32]. Our work might also be beneficial for the design of balanced experiences between players and digital non-player characters. Lastly, our work could also be used to incorporate social support in interactive rehabilitation systems to bring together users with different physical limitations and also to include patients' social networks, with those who have no injuries, in the rehabilitation activity. In the next section, we describe prior work on balancing participants' abilities in both computer games and in sports literature, identifying the need for a systematic understanding of how to design for balanced exertion experiences. 


\section{BALANCING DIFFERENT SKILLS AND ABILITIES}

Balancing different skills and abilities in exertion activities is not new: it exists in many sports in the form of handicapping. With handicapping, players apply different scoring rules to participants to equalize the chance of winning, and in doing so maintain a level of fair play for less experienced players.

Balancing can be an established practice, for example almost all golfers, except professionals, use handicaps. The classification system used in the Paralympics is another well-established strategy for balancing participants with different physical abilities. Handicapping can also be more ad-hoc, for example pick-up basketball players count the scoring of less-skilled players twice. Joggers sometimes wear weights to balance their pace to their partner's. Yet, the use of interactive devices for these forms of balancing has been mainly limited to basic calculators, calculating balancing formulas, as seen in the many golf handicap calculators offered online.

Interactive systems have aimed to offer experiences that are balanced to users' efforts and abilities. These are observed mainly in computer adaptive testing and learning. More recently, the concept of balancing has become prominent in entertainment systems $[3,12]$. Probably one of the earliest forms of balancing in computer games is the option for players to select their difficulty level at the beginning of a game (easy, normal or hard). Unlike in sports, this balancing is player-driven and is based on a player's perceived abilities. However, it can be difficult for a player to know which level to select, as predicting future performances is not easy, resulting in experiences that are either too demanding or not challenging enough. Game designers have tried to address this issue using Dynamic Difficulty Adjustment (DDA). DDA takes performance data from the game, analyzes it and deploys an algorithm to adjust the game's difficulty as a result [10]. However, designing and implementing an effective DDA system in games is not trivial [6] - players often feel "cheated" by the balancing functionality [10], and exertion games are no exception [29]. Nevertheless, DDA is an interesting approach that moves control of balancing from the hands of the player or game designer to the interactive system itself. Unfortunately, most of the research on DDA appears to be focused on single-player experiences [6] even though many current consoles seem to support a trend towards more social play, where family members and friends play together, often with very different play skills and abilities [32]. This suggests that research on balancing could enhance our understanding of the social play experience.

Recent advances in computing and sensing technology have led to systems that utilize some of the balancing features of computer games to motivate people to be more physically active. Mobile jogging apps on smartphones now offer balancing features, for example the Nike+ system tracks a runner's pace and allows him or her to make comparisons with other joggers [2]. When not jogging, the user can engage with an online community system that allows balancing of participants who want to run at different times and also along different track lengths. It allows competing for different targets such as "fastest mile" and "who reached 100 miles first".

Research projects such as Ubifit [7] showed that technology could motivate people to invest increased physical effort, however, they did not consider participants' disparate fitness levels. The Swan Boat project explores balancing between multiple treadmill runners by presenting a virtual game that requires both balanced and non-balanced exertion investment in the form of speeding up and slowing down as motivated by the game, based on the author's assumption that motivating a change in running pace makes the experience more "exciting" [1]. Projects such as Life is a Village explore "asymmetric roles" [31] of participant input to allow players with different exercise preferences to play together: one cycles, the other makes "throwing" movements with a Wiimote [34]. These systems demonstrate that different exertion activities can be balanced, however, intertwining social gameplay and exertion in these experiences have yet to be explored.

Closest to our work is the research around Heart Burn [31], an exercise-bike-powered competitive game for two players that balances participants' fitness levels through heart rate data relative to resting rate. The authors found that this approach to balancing can reduce the gap between people of disparate fitness levels while not negatively impacting players' engagement with the game.

Prior research therefore shows that balancing different fitness levels is possible, and that it can contribute to an engaging experience. However, none of the prior research presents a systematic understanding of how to design for these balanced experiences. Our work aims to address this gap by providing a framework for designing balanced exertion experiences. In the next section, we describe our prototype system, Jogging over a Distance, which served as research vehicle for our investigation into balanced exertion experiences.

\section{JOGGING OVER A DISTANCE}

The Jogging over a Distance system has been previously described in detail $[19,20]$. In summary, two jogging partners arrange to run at the same time, wearing stereo headphones, a microphone and a heart rate monitor. They also wear a small running bag, containing a mini computer and a mobile phone. Before the run, users need to enter their preferred target heart rate, which stands for the physical effort they plan to invest based on their fitness levels and goals. While the participants jog, their heart rate data is sent to a server, analyzed and then sent to the other jogger. Each jogger can hear the audio of their jogging partner. The participants' heart rate data in relation to their target heart rate affects the position of the audio in a 2D plane that is oriented horizontally around the jogger's head. The spatialization is achieved through binaural software 
that places the sound source in a $2 \mathrm{D}$ audio environment, moving around the jogger's head from the front, to side-byside and to the back depending on the difference of the relative heart rates. If the other jogger is "in front", the sound appears to come from the front. The further "in front" the jogger is, the lower the volume of the audio becomes. When both joggers are at their target heart rate, they hear the audio at full volume as if they were running side-by-side. The same applies when both joggers divert from their preferred heart rate at the same percentage, for example, if both joggers raise their heart rate to $110 \%$, the audio stays in the center. However, if one partner's heart rate becomes greater, relative to their individual target heart rates, she/he will hear the audio fall behind her/him, and his partner will hear the audio move ahead. This perceived "distance" between the pair increases with the difference in their target-relative heart rates.

We used heart rate as input rather than speed as we noticed with an earlier version of Jogging over a Distance that used pace data [19] that participants can become confused when one of them is running uphill, because they were wondering why their partner's breathing was intensified although their audio moved to the "back", indicating a slowing down. In consequence, we redeveloped the system using heart rate data in relation to the target heart rate [21]. This resulted in intensified breathing relating to increased effort representation, i.e. people who put more effort in were moving to the "front" in the audio space, regardless of whether they were speeding up or running up a hill, addressing the confusion from the previous system.

\section{STUDY}

Our initial study focused on how the design features of Jogging over a Distance facilitated a shared experience [21]. Since then, we have studied more runs and collected more data in order to understand how to design for a balanced exertion experience.

\section{Participants}

We recruited volunteers who usually jog with a friend and do not regularly participate in competitions. We focused on social joggers because we believe they are the most suitable target group for a system that combines jogging with social interaction. In total, we report on 22 runs by 32 participants. 5 joggers wanted to run a series of runs with different partners, which we welcomed and marked in the analysis.

All pairs had prior social relationships: they were either friends or siblings. The participants were all volunteers and they were not monetarily compensated. The joggers were between 23 and 44 years old, 14 participants were female and 18 were male. Their jogging experience varied equally from jogging regularly between 2-4 times a week (16 participants), to others running only occasionally (16 participants). Fourteen runs were with participants in the same city, where jogging partners were asked to run in opposite directions along their usual jogging paths to simulate an "over a distance" experience. The other eight runs were with participants separated by large distances, mostly where one jogger was in Australia and their partner in Europe.

\section{Procedure}

Participants were asked to run at their usual location, which was always a public park without any car traffic. The system asked the participants if they had a preferred heart rate they would like to run at. If they did not know their target heart rate, we provided them with a heart rate monitor before the study to let them determine which heart rate they would be most comfortable with. The target heart rates entered ranged from 130 to 175 beats per minute, where none of the participant pairs had entered the same heart rate except two pairs (Table 1). Even though these joggers were not balanced based on their target heart rate, we were curious how they would use the system. The average target heart rate was 158 beats per minute across all runs, and the average difference between pairs was 8 beats per minute $(\mathrm{SD}=6)$. Each run was between 25 and 45 minutes long, with an average of 30 minutes.

\begin{tabular}{|c|c|c|c|c|}
\hline Participant & $\begin{array}{l}\text { Tar- } \\
\text { get } \\
\text { heart } \\
\text { rate }\end{array}$ & $\begin{array}{l}\text { jogged with } \\
\text { participant }\end{array}$ & $\begin{array}{l}\text { Tar- } \\
\text { get } \\
\text { heart } \\
\text { rate }\end{array}$ & $\begin{array}{l}\text { Del- } \\
\text { ta }\end{array}$ \\
\hline 1 (Melbourne) & 145 & 2 (London) & 155 & 10 \\
\hline 1 (Melbourne) & 160 & 2 (London) & 155 & 5 \\
\hline 1 (Melbourne) & 145 & 2 (London) & 155 & 10 \\
\hline 1 (Melbourne) & 145 & 2 (London) & 155 & 10 \\
\hline 1 (Melbourne) & 145 & 3 (Melbourne) & 155 & 10 \\
\hline 1 (Melbourne) & 155 & 4 (Melbourne) & 162 & 7 \\
\hline 4 (Melbourne) & 160 & 5 (Freiburg) & 147 & 13 \\
\hline 6 (Melbourne) & 157 & 7 (Melbourne) & 158 & 1 \\
\hline 6 (Melbourne) & 160 & 8 (London) & 155 & 5 \\
\hline 8 (London) & 155 & 9 (Melbourne) & 145 & 10 \\
\hline 10 (Melbourne) & 155 & 11 (Melbourne) & 160 & 5 \\
\hline $12(\mathrm{M}$ & 160 & 13 (Melbourne) & 162 & 2 \\
\hline 14 (Melbourne) & 162 & 15 (Melbourne) & 172 & 10 \\
\hline 16 (Melbourne) & 165 & 17 (Melbourne) & 165 & 0 \\
\hline 18 (Melbourne) & 165 & 19 (Melbourne) & 165 & 0 \\
\hline 20 (Melbourne) & 165 & 21 (Melbourne) & 167 & 2 \\
\hline 22 (Melbourne) & 150 & 23 (Melbourne) & 170 & 20 \\
\hline 24 (Melbourne) & 130 & 25 (Melbourne) & 150 & 20 \\
\hline 26 (Melbourne) & 151 & 27 (Melbourne) & 170 & 19 \\
\hline 28 (Melbourne) & 153 & 29 (Melbourne) & 162 & \\
\hline 30 (Melbourne) & 170 & 31 (Melbourne) & 167 & 3 \\
\hline 32 (Sydney) & 174 & 30 (Melbourne) & 175 & 1 \\
\hline
\end{tabular}

Table 1. List of participants' target heart rate differences.

\section{Data Collection and Analysis}

Upon their return from the jog, participants were interviewed together. If they were in separate locations then one participant was dialled-in with a speakerphone. We also analysed the heart rate $\log$ data and the recorded participants' interactions over the audio channel during the 
run in order to understand how their experience unfolded throughout the activity. We included our participants in the data analysis process to better understand their experience by discussing together their logged heart rate data to unpack how their experience evolved throughout the run.

\section{EXPERIENCING BALANCED EXERTION}

Participants expressed that they enjoyed taking part in the Jogging over a Distance experience. As we found with the initial subset of the data, participants reported that they were running "together" rather than alone, despite the physical distance between them [21]. The participants applauded that it was a balanced experience, expressing delight such as:

"In a sense it was better [than co-located jogging] because I could just do my own thing and run and not have to worry, for example if I'm running with [person's name], I am running too fast or too slow, I could just run at my own pace. " "[...] because if you're with somebody too fast or too slow I think it frustrates everybody to a degree." [interview]

The balancing allowed for jogs between participants who usually could not run together in an equitable way:

"I'm not able fitness wise to jog with [partner's name] at [partner's name]'s chosen pace but [now] we were still having that interaction." [interview]

We now describe the different elements that came together for our participants in making running with Jogging over a Distance a balanced experience, and also highlight elements that did not work for our joggers.

\section{Breathing}

Participants were affected by hearing their partner breathing more intensively throughout the jog. They commented on each other's puffing during the run: "I can hear you panting" [run] and "You've got the giving-birth breathing going, are you alright?" [run].

Due to the placement of the microphone and the focus on the audio, the breathing was amplified for the participants: "It makes you focus on hearing someone else in pain." [interview]

The participants explained how they used this awareness of their partner's amplified exhaustion level to balance their physical investment:

"[Partner's name] was getting tired and I was saying 'That's ok, go whatever speed you need to' and I would slow down" [interview]

This awareness of their partner's exhaustion level led participants to feel empathy for their partner, which motivated them to negotiate a more balanced experience. This often involved a deliberate slowing down by the fitter participant, who was willing to compromise his or her exertion investment for a more enjoyable run for the partner.

\section{Competing}

Three of our participant pairs stated that their entire jog was one of competition. Most others stated that competition played a role at some stage of the activity:

"If you were in front, there wasn't the slow down option." "Yeah, it was competitive." [interview]

In addition to breathing, the participants were also aware how their partner's body responded to the exertion activity through the conveyed heart rate data. Unlike in co-located jogging, participants' heart rate was made "visible" through the sensing technology. The difference between the breathing and the heart rate data was that the heart rate data was not only conveyed, but also quantified and hence comparable for the participants. This facilitated competitive behavior: "I just tried to beat her all the time. I just tried to keep her behind me." [interview]

This is not surprising considering that sports activities can often revolve around competition. Two participant pairs expressed that they were for the first time able to engage in a competitive run together, as their fitness levels differ too much to compete with one another when they are colocated.

\section{Collaborating}

Our joggers also ran socially. For most participants and for the majority of the time "it was collaborative." [interview]

One pair tried to be more competitive, but the representation of the heart rate data in an audio space made competition difficult for them. The spatialization allowed joggers to determine if their partner was in front or behind, but identifying small differences in sound positions was difficult. As a result, this pair abandoned the idea to compete and decided to "make it a social run" [run].

\section{Achieving Fitness Goals}

Our participants applauded that the Jogging over a Distance system allowed them to balance their social experience without sacrificing their individual fitness goals. In particular, one pair commented on how they previously had to compromise due to one person's injury:

“Because when we normally [run], [partner's name] had this thing with her toe and so I had to slow down. [Now] we can exercise the way we want to exercise or go the direction we want to go without being constrained." [interview]

\section{Altering the Jogging Route}

Participants felt motivated to alter the way they ran; in addition to speeding up and slowing down, they also scanned their environment to identify any opportunities to increase their heart rate, for example running up hills or stairs: 
"If I was too slow, I would pick up speed again or I would chose to walk up a hill at least to get the heart rate right." [interview]

"I was searching my environment for something that would actually enable me to raise my heart rate. I was looking for more of a challenge, similar to her challenge [...] because you want to be able to relate it in some way, you want to validate it." [interview]

When participants chose to alter the jogging route by actively seeking hills while maintaining pace (in contrast to participants who slowed down on slopes to keep their heart rate constant), they "moved to the front" in the audio space. This was often interpreted as a challenge to race one another, which was welcomed by competitive participants, contributing to the experience. In that sense, participants opted to increase their respective challenges - motivated by how they perceived their partner's effort investment. By doing so, participants felt they also learned more about how their heart rate responds to physical activity: "My heart rate comes up pretty quickly these days." [interview]

\section{Exercise Duration}

Participants were excited about being able to run at different speeds. However, the system did not support them if they wanted to run for different durations. Our joggers had two main strategies for balancing different exercise duration preferences:

a) Most participants negotiated their exercise duration before the run, as we had suggested. This resulted in some participants choosing to run faster than their usual speed in order to "make up" for the shortening in time. However, running faster is not the same as running longer. For the participants with varying duration preferences, the inability of the system to support different jogging durations resulted in them compromising their exercise goals in order to have a balanced experience.

b) When participants could not achieve the same exercise duration, for example if one jogger had not yet reached home, they would leave the audio channel on and the runner who had completed the run would motivate the other verbally to keep them going.

\section{CREATING BALANCED EXERTION EXPERIENCES}

We now discuss ways of creating balanced exertion experiences based on the insights gained from studying the use of Jogging over a Distance. Based on our analysis of the user experience, we believe that the key to facilitating an engaging social exertion experience is to support exertion that is challenging, but not overly strenuous for participants. In this sense, interactive systems can help participants enter the "flow zone", in which skill and challenge levels are aligned [8].

We begin by considering the ways in which interactive systems could facilitate balanced exertion experiences as a set of dimensions: Measurement, Presentation, Adjustment and Control. Based on our study of Jogging over a Distance, we present broad aspects of these dimensions, describing a design space. To aid designers in navigating this space, we also use these dimensions to articulate a set of design tactics. These are based on our craft knowledge of designing and deploying Jogging over a Distance.

\section{Dimension 1: Measurement}

In order to balance exertion experiences, exertion needs to be sensed and measured so that it can be used as input. Measurement is therefore our first dimension and deals with how exertion is measured. Based on previous work and our study data, we identified two broad aspects of how exertion could be measured and discuss their effects on the exertion experience:

\section{Performance}

The traditional sports-model of balancing measures performance and subsequently adjusts the scoring. Balancing through measuring performance can be welcomed by competitive-oriented participants who also go jogging without augmentation. For example, one jogging pair in our study, who was training for a "fun run", wished not heart rate but performance would be measured, as this would allow them to track their performance across their run history and so enable comparisons with their training plan objectives.

\section{Effort}

Jogging over a Distance does not measure pace data, but instead uses heart rate data to get a sense of people's physical effort. By changing what is measured of the exertion activity, from pace to heart rate, the system changed the focus from performance output to effort input, and as a result, reduced the impact physical abilities have on the experience. On the extreme end, this dimension accommodates the balancing of completely different exertion activities [30]: we successfully trialed using the Jogging over a Distance system with one person jogging, the other cycling.

The recent increase in the availability of sensors that can measure a wide range of exertion data, in particular data from the "responding body" [18] such as ECG, breathing rate and skin temperature, gives designers new opportunities for measuring and hence balancing exertion activities. Furthermore, the Jogging over a Distance study suggests that by balancing exertion activities using these types of sensors could also enhance people's understanding of how their bodies respond to exercise, hence contributing to kinesthetic literacy [28]: participants expressed that they learned about their heart rate and how it responds to jogging. Such knowledge could motivate engaging in other physical activities, for example one participant pair tried star jumps to see how this would affect their heart rate. 


\section{Dimension 2: Presentation}

In order to create a balanced experience, designers not only need to consider what they measure, but also how the balanced measurement is presented to the participants. Designers need to consider if participants should know that their exertion is balanced, and if so, how this should be presented. Technology provides designers with many opportunities to hide or reveal balancing to exertion participants. In particular, mediated exertion activities can lean on awareness systems, as Jogging over a Distance demonstrated.

We identified two broad aspects on how to present balanced measurements to participants. They sit on almost opposite ends of a dimension, with many opportunities for technology to facilitate awareness between the two extremes.

\section{Explicit}

In Jogging over a Distance, participants were aware of the balancing because they had to enter their target heart rate into the system before the run. However, this awareness appeared to have diminished over the course of the run, which became apparent when participants, who were colocated and hence ran in opposite directions, met at the finish-line at different times and were confused: the audio space gave them the impression they were side-by-side, however, the timing told them they were not.

\section{Hidden}

Designers can also choose to limit participants' awareness of any balancing. In the extreme case, no awareness could be provided, in essence hiding the balancing from the participants. Hidden presentation could be used to "trick" exertion participants into investing more effort than they allow themselves. Possible application scenarios are training sessions where the trainer wants to help the athlete to overcome performance issues by pushing her beyond her limits. However, whether balancing participants without their knowledge is ethical behavior for designers is an open question we would like to raise.

\section{Dimension 3: Adjustment}

Designers not only need to ask what they measure and how to present it, they also need to consider how they adjust the measurement for balancing. There are many ways to adjust these measurements: they range from simple offsets to complex calculations. In Jogging over a Distance, the heart rate measure was adjusted in relation to the target heart rate. Other designs of exertion systems use more multifaceted formulas, sometimes including the resting heart rate based on participants' age in their formulas [31]. When it comes to sensor measurements, such as when sensing heart rate, balancing might require specific adjustments to consider the sensor's characteristics, for example to accommodate the fact that heart rate change occurs only after a short delay [31].

\section{Static}

The most common way of adjustment is probably the application of a static modifier to the exertion data; in conventional sports this is most often a multiplier to the score of a weaker player. Such adjustments to balance players are easy to implement, and easy for participants to understand, facilitating a predictable challenge throughout the activity.

\section{Dynamic}

Recent technology advancements enable dynamic adjustments throughout the exertion activity. The interactive system can continuously measure exertion levels and adjust the balancing to facilitate the most engaging experience at any one moment, based on how the body responds to the activity. However, achieving this so that participants feel challenged while still being in control of their experience is an ongoing question for future research.

Static and dynamic are only two positions on the adjustment continuum; there are many other ways in which designers could implement adjustment. For example, designers could re-balance only at fixed intervals, allowing participants to strive for static targets in the form of minigoals [4], while at the same time considering how fatigue affects participants differently over time.

\section{Dimension 4: Control}

Jogging over a Distance showed that it is not the designer alone who has a role in balancing the exertion experience; exertion participants themselves can also play an active role in balancing exertion. As a result, our final dimension is one of control, asking who is controlling the balancing.

\section{Designer}

Designers can choose to control the balancing. In many heart rate-balanced games $[16,23,31]$, the designer of the system is in control of the balancing, for example by predetermining the balancing based on participants' age. Being in control of the balancing allows designers to actively facilitate health benefits: in Heart Burn [31] the designer controls the balancing so that the participants' heart rates stay in the aerobic zone.

\section{User}

On the other end of the dimension is the user in control of the balancing. The system's design can facilitate this: in Jogging over a Distance participants had to enter their target heart rate themselves, which some of the multiple-run joggers changed for each run, in particular when the weather was hotter than on the previous runs or different at the remote location, or when they felt tired on that particular day. Some joggers wished they were able to adjust their target heart rate during the run as well, in order to balance if their partner got tired at a different rate. Giving users control of the balancing can facilitate a feeling of agency over their experience, but the design also needs to facilitate the challenge arising from exertion and possibly 
consider cheating behavior [5]. Managing this relationship successfully is an interesting topic for future research.

\section{Tactics for Balancing Exertion Experiences}

We now present six design tactics we derived from our craft knowledge of designing and deploying Jogging over a Distance. These are aimed at helping designers navigate the design space in order to make good choices when creating balanced exertion experiences. We describe them using the dimensions.

\section{Tactic 1: Facilitate Empathy}

If people can become aware of the exhaustion level of their partner, in particular regarding any overexertion, empathy can develop. This can lead participants to adjust their exertion to a more mutually suitable level. By doing so, designers can facilitate a sense of control (dimension: Control) for participants in shaping the experience.

In Jogging over a Distance, breathing was sensed through the microphone (Measurement). This breathing was amplified (Adjustment) by the design of the system. Firstly, as participants were not able to see their partner, their focus was directed to the audio. Secondly, the placing of the microphone captured the breathing sound close to its source, and the delivery over headphones made participants more aware of their partner's puffing, so that exhausted participants appeared to be more exhausted (Presentation). As a result, participants voluntarily slowed down for their partner. Future research could investigate how participants' awareness (Presentation) of the breathing being amplified (Adjustment) affects their own breathing: will they try to suppress their breathing to motivate their partner?

\section{Tactic 2: Represent Exertion in Low Resolution}

Deliberately representing exertion in low resolution can be beneficial for balanced experiences. For example, the design choice in Jogging over a Distance to represent heart rate data (Measurement) as locations in an audio space (Presentation) reduced the ability to identify changes in sound positions if the heart rate changed only slightly. This made close comparisons difficult, resulting in participants not focusing on finicky performance details as so often featured on mobile jogging apps that focus solely on competition. Rather, the participants saw and treated the activity as a social jog.

Representing exertion in low resolution is one way of introducing ambiguity to the design of balancing. The benefit of ambiguity as a resource for design in HCI has previously been highlighted [9]. Our paper extends this work by presenting evidence that "ambiguity of information" [9] can be a powerful tactic to facilitate collaborative exertion engagement.

\section{Tactic 3: Support Varying Levels of Exertion}

Exertion experiences can benefit from participants being able to vary their levels of exertion. This seems obvious in Jogging over a Distance, where participants were able to speed up or slow down in response to the balancing. However, the joggers also found other creative ways to alter their heart rate: they looked out for a hill or a flight of stairs that they could run up. The joggers used the external world as a resource to rapidly increase their heart rate, but this came with the risk of exhausting oneself too quickly. The design of Jogging over a Distance facilitated this in two ways: firstly, it measured heart rate (Measurement), which supports varying levels of exertion largely independent from the activity, like the joggers who did star jumps. Secondly, Jogging over a Distance is a mobile system and hence allows for outdoor jogging, giving participants many more resources to increase their heart rate compared to indoor treadmill running. These resources became choices for participants, and they were curious to see how their choices affected their own and their partner's run. The benefit of choice is in line with computer games theory that suggests that having interesting choices makes for engaging gameplay [26].

Designers of future systems could support varying levels of exertion by offering a range of physical resources, for example by making available a set of weights participants could wear, but possibly also virtual resources such as virtual power-ups.

\section{Tactic 4: Exploit a Shared Space}

Designers can use technology to adjust (Adjustment) the exertion measurements (Measurement) from the participants in a way that they are represented (Presentation) in a shared space. This shared space then enables balanced interactions not possible without it.

In Jogging over a Distance, the spatialization created a virtual audio world that facilitated the sensation of a "third place" where participants tried to bring the two audio sources into the middle. Participants described it as a game that they were "trying to beat". Beating the game meant keeping the audio source at the same level, meaning that participants perceived (Presentation) the system balancing their competitive engagement towards the game, rather than against each other.

Mobile phone apps lend themselves to exertion activities due to their mobility factor, however, shared spaces are not often implemented, possibly due to the limited screen size. However, Jogging over a Distance showed that large screens and rich graphics are not necessarily needed to create a shared space for exertion.

\section{Tactic 5: Negotiate Duration}

Exertion has a very temporal characteristic, it usually begins at a specific time, and our bodies can only engage in it for so long. This poses a challenge when balancing exertion activities, since participants might want to engage for different durations. For example, the Jogging over a Distance system was designed with equally long runs in mind. However, we learned that participants often prefer different exercise durations, so we encouraged participants 
to negotiate beforehand how long they would like to run for. By encouraging participants to balance their exertion duration in this way, we managed to facilitate a balanced experience between most of our participant pairs when it came to the exercise's duration. However, the system clearly fell short in supporting participants who wanted to run for very different durations.

HCI research has a long history in supporting activities of different durations in the form of asynchronous interactions [27]. The Jogging over a Distance work raises the question whether HCI could propose exertion systems where the physical investment does not assume the same time investment between participants while still facilitating the sensation of a social experience. In our own work with Pushing Pixels [28], we explored the opportunities of technology to support asynchronous interactions between bodybuilders. While we have shown that asynchronous exertion activities are possible, we assume equal exertion duration. Designers might explore balancing aspects such as "stretching time" (Adjustment) to accommodate different exercise lengths, as engaging in exertion can affect how people perceive time, for example athletes can experience a distorted sense of time in the "flow zone" [8].

\section{Tactic 6: Exploit Physical Risk}

Designers should consider physical risk when balancing, both from the perspective of avoiding injury, but also as a design resource. In Jogging over a Distance, participants exposed themselves to the risk of overexertion. The joggers commented on the intense puffing they could sometimes hear, which resulted in them encouraging their partner to slow down to avoid any injuries. However, it could also be the interactive system (Control) that detects unhealthy exhaustion levels and triggers adjustments to the balancing (Adjustment) so that participants are motivated to reduce their effort investment.

The potential of considering physical risk in HCI has previously been highlighted [11, 15, 18]. Using risk as a design resource could mean that risky moves in an exertion activity could be measured (Measurement) and consequently considered in the balancing adjustment (Adjustment), enabling exertion experiences between riskseekers and risk-averse participants.

One important point we would like to highlight in terms of balancing and physical risk is the open question of how balancing affects people's perceived abilities: for example, if participants' input into a system is balanced but the output is conveyed in a way that the participants perceive it to be their true ability, they might overestimate their physical abilities when engaging in other, non-balanced exertion activities, possibly causing injuries. We believe issues such as these are important considerations for designers when balancing exertion systems.

\section{CONCLUSIONS}

We have described the study of a distributed joggingsupport system that aims to facilitate a balanced exertion experience. The participants found that balancing facilitated an engaging experience and enabled a social activity they often could not achieve when they were co-located due to different fitness levels. As such, the distance between them was not something the technology "fixed", but rather an enabler for a novel exertion experience.

By analyzing participants' experiences, we have been able to unpack the key factors that made balanced jogging an engaging experience. With these key factors, we derived a set of dimensions that create a design space for balanced exertion experiences. This design space and associated design tactics may be particularly useful for designers who want to facilitate engaging social experiences around existing exertion activities, but they could also be used to balance users across different physical activities, such as enabling joggers and cyclists to engage in exertion activities together. This might expand the range of possible activities and hence partners for people eager to be physically active but lacking an exercise partner. Our work could also be useful for the growing interest in supporting intergenerational physical activities, balancing between different fitness levels of different age groups.

Our work aims to appreciate our bodily differences. Even though we balance different fitness levels, we are not trying to reduce the bodies involved to a level where they and their actions are all "the same"; after all, participants still have to invest physical effort. We hope with our work we are able to sensitize interaction designers to the fact that our bodies are all different, proposing a heightened appreciation of asymmetry in interactive experiences that celebrates the many different types and shapes of bodies we inhabit.

We hope our work on balancing aids designers in creating social exertion systems that users find engaging, increasing participation in physical activity and consequently allowing them to profit from the many benefits of exertion.

\section{ACKNOWLEDGEMENTS}

We would like to thank Andreas Paepcke, Scott Klemmer, Terry Winograd, Yvonne Rogers, Steven Dow, Wendy Ju, BJ Fogg, Shannon O’Brien, Alex Thorogood, Fulbright, the Melbourne University Graduate School, the Australian Research Council and the London Knowledge Lab.

\section{REFERENCES}

1. Ahn, M., Kwon, S., Park, B., Cho, K., Choe, S., Hwang, I., Jang, H., Park, J., Rhee, Y. and Song, J. Running or gaming Conference on Advances in Computer Enterntainment Technology (ACE '09), ACM, Athens, Greece, 2009, 345-348.

2. Apple. Apple - Nike + iPod, Retrieved from http://www.apple.com/ipod/nike. 
3. Bateman, S., Mandryk, R.L., Stach, T. and Gutwin, C. Target assistance for subtly balancing competitive play. In Proc. CHI 2011, ACM Press (2011), 2355-2364.

4. Bogost, I. The Rhetoric of Exergaming Digital Arts and Cultures (DAC) Conference, Denmark, 2005.

5. Campbell, T., Ngo, B. and Fogarty, J. Game design principles in everyday fitness applications. In $C S C W$ 2008, ACM Press (2008), 249-252.

6. Chen, J. Flow in Games (Thesis), 2008.

7. Consolvo, S., Everitt, K., Smith, I. and Landay, J.A. Design requirements for technologies that encourage physical activity. In Proc. CHI 2006, ACM Press (2006), 457-466.

8. Csikszentmihalyi, M. Flow: The psychology of optimal performance. New York: Harper and Row, 1990.

9. Gaver, W.W., Beaver, J. and Benford, S. Ambiguity as a resource for design. In Proc. CHI 2003, ACM Press (2003), 233-240.

10. Hunicke, R. The case for dynamic difficulty adjustment in games, ACM, 2005, 429-433.

11. Klemmer, S. and Hartmann, B. How Bodies Matter: Five Themes for Interaction Design. In Proc. DIS 2006, ACM Press (2006), 140-149.

12. Kraaijenbrink, E., van Gils, F., Cheng, Q., van Herk, R. and van den Hoven, E. Balancing Skills to Optimize Fun in Interactive Board Games INTERACT 2009, Springer, 2009, 301-313.

13. Lin, J., Mamykina, L., Lindtner, S., Delajoux, G. and Strub, H. Fish'n'Steps: Encouraging Physical Activity with an Interactive Computer Game. In UbiComp 2006, 261-278.

14. Lindley, S.E., Le Couteur, J. and Berthouze, N.L. Stirring up experience through movement in game play: effects on engagement and social behaviour. In Proc. CHI 2008, ACM Press (2008), 511-514.

15. Marshall, J. and Benford, S. Using fast interaction to create intense experiences. In Proc. CHI 2011, ACM Press (2011), 1255-1264.

16. Masuko, S. and Hoshino, J. A fitness game reflecting heart rate. Conference on Advances in computer entertainment technology, ACM Press (2006), 53.

17. Mueller, F., Agamanolis, S. and Picard, R. Exertion Interfaces: Sports over a Distance for Social Bonding and Fun. In Proc. CHI 2003, ACM Press (2003), 561568.

18. Mueller, F., Edge, D., Vetere, F., Gibbs, M.R., Agamanolis, S., Bongers, B. and Sheridan, J.G. Designing Sports: A Framework for Exertion Games. In Proc. CHI 2011, ACM Press (2011), 2651-2660.

19. Mueller, F., O'Brien, S. and Thorogood, A. Jogging over a Distance: Supporting a "Jogging Together" Experience Although Being Apart. In Proc. CHI 2007, ACM Press (2007), 2579 - 2584.
20. Mueller, F., Vetere, F., Gibbs, M.R., Agamanolis, S. and Sheridan, J. Jogging over a Distance: The Influence of Design in Parallel Exertion Games. SIGGRAPH 2010, ACM Press (2010).

21. Mueller, F., Vetere, F., Gibbs, M.R., Edge, D., Agamanolis, S. and Sheridan, J.G. Jogging over a distance between Europe and Australia. In Proc. UIST 2010, ACM Press (2010), 189-198.

22. Nachman, L., Baxi, A., Bhattacharya, S., Darera, V., Deshpande, P., Kodalapura, N., Mageshkumar, V., Rath, S., Shahabdeen, J. and Acharya, R. Jog Falls: A Pervasive Healthcare Platform for Diabetes Management Pervasive Computing, Springer, 2010, 94111.

23. Nenonen, V., Lindblad, A., Häkkinen, V., Laitinen, T., Jouhtio, M. and Hämäläinen, P. Using heart rate to control an interactive game. In Proc. CHI 2007, ACM Press (2007), 853-856.

24. O'Brien, S. and Mueller, F. Jogging the distance. In Proc. CHI 2007, ACM Press (2007), 523-526.

25. Porcari, P., Foster, C., Dehart-Beverly, M., Shafer, N., Recalde, P. and Voelker, S. Prescribing Exercise Using the Talk Test, n.d. Retrieved from http://www.fitnessmanagement.com/FM/tmpl/genPage.a $\mathrm{sp}$ ? $\mathrm{p}=$ /information/articles/library/cardio/talk0801.html.

26. Salen, K. and Zimmerman, E. Rules of Play: Game Design Fundamentals. The MIT Press, Boston, MA, USA, 2003.

27. Sears, A. and Jacko, J. The Human-computer interaction handbook. Lawrence Erlbaum Associates, Mahwah, New Jersey, USA, 2008.

28. Sheridan, J. and Mueller, F. Fostering Kinesthetic Literacy Through Exertion Games Workshop on WholeBody Interactions at CHI 2010.

29. Sinclair, J. Feedback control for exergames (PhD thesis), 2011.

30. Song, J., Ubiquitous Games Research. http://nclab.kaist.ac.kr/UGAME/.

31. Stach, T., Graham, T., Yim, J. and Rhodes, R.E. Heart rate control of exercise video games Proceedings of Graphics Interface 2009, Canadian Information Processing Society, 2009, 125-132.

32. Voida, A. and Greenberg, S. Wii all play: The console game as a computational meeting place. In Proc. CHI 2009, ACM Press (2009), 1559-1568.

33. Weinberg, R.S. and Gould, D. Foundations of Sport and Exercise Psychology. Human Kinetics, Champaign, IL, USA, 2006.

34. Yim, J. and Graham, T.C.N. Using games to increase exercise motivation Proceedings of the 2007 conference on Future Play, ACM New York, NY, USA, Toronto, Canada, 2007, 166-173. 